\title{
Predictors Of Social Networking Sites (SNS) Influence For Restaurant Industry
}

\section{Pallavi Dogra ${ }^{a}$}

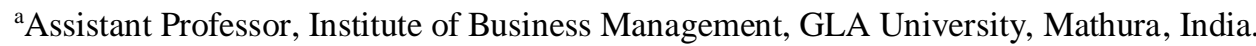
E-mail: pallavi.ibm@gla.ac.in

Article History: Received: 11 January 2021; Accepted: 27 February 2021; Published online: 5 April 2021

\begin{abstract}
Social networking websites serve the purpose of connecting with each other. But nowadays it serves various other uses such as marketing purpose, shopping platform, review engine and many more. The main aim of the present paper is to explore the factors that affect the customers visit towards the restaurant influenced due to reviews mentioned on the social networking websites. Primary data was collected from 332 respondents belonging to the cities such as Mathura, Agra, Firozabad, and Allahabad. Non disguised questionnaire was used for the data collection purpose. Exploratory factor analysis has been applied on the collected data. The results of the study found five factors such as SNS Engagement, Conformity to trend, Social Prestige, Quality Perception, social influence on SNS which are affecting the customer's views towards restaurant reviews.
\end{abstract}

Keywords: Quality Perception, Restaurant, Reviews, Conformity, Social Networking Websites.

\section{Introduction}

Social media facilitates the user to share or exchange information by giving positive or negative word-ofmouth (WOM) about the various products and services. Now a day's SNS creates an important avenue for the facilitation of global social interconnections (De Bruyn, 2008). Hermkens et al. (2011) discussed that social media constructs the goodwill of the company by promoting its products and services on the websites. WOM communication is useful to shape consumer behavior and it is considered one of the powerful tools for the advertising and promotion of the product and services (Dellarocus, 2003). The techniques which are widely used on social networking platform consist of "electronic word-of-mouth (e-WOM)", "viral marketing" and "relationship marketing" which help marketers in applying social networks for referral marketing (De Bruyn \& Lilien; 2008). Harris and Rae (2009) suggested that the future of marketing is dependent upon the social network channels due to modern touch, accessibility, and more reach among the audience.

Social media is making a stronger presence in the case of the hotel and restaurant industry which is influencing the consumer visit, re-visit, recommendations about the service provider (Akehurst, 2009; Huang, 2011; Hudson \& Hudson, 2013). Furthermore, Hays et al. (2013) suggested that social media is on the testing stage with a high percentage of variation in the term of strategy. Consequently, it is required that social networking sites should be more involved in the conversation, reviews, sharing the restaurant area, and pictures which will help the prospective customers. The planned activity helps to build an organization image different in a high tech world in a constructive manner. Therefore, relationship marketing is extensively used in emerging and competitive markets all over the world by service providers, firms, to have thriving affairs with the customers.

Companies use social networking websites to gain knowledge about human mindset, actual wants of the customers so that they can be converted into loyal customers. This helps to maintain a positive relationship by elevating consciousness and winning the reliabilities and faith of their customers. Henceforth, Social Media are gaining momentum as they are the most persuasive platforms for obtaining customer attention. The trend of using social networking websites as a reference for shopping is increasing day by day. Customers are more inclined towards online shopping as they can compare rates and rank products because of visible information and reviews available on these highly interactive websites.

The current environment involves a lot of challenges on business organizations so that they can adjust to social media when it is affecting their purchase decisions. Social media networks are offering enormous potential for users and organizations to get closer to each other and offer mutual benefits at a lower cost, income, and efficiency gains. To get the most out of it the advantage of these social center organizations is facing a challenge to align their strategies with the changing nature of customers. Before performing it organizations must understand the magnitude of the relationship between social networks, social networks, and consumers' decision processes. Therefore, in the present paper efforts had made to identify the predictors which will make the people visit restaurant due to the marketing done by service providers on social networking websites. Further, if they are 
satisfied they share their restaurant visit experience on the social networking websites, in the form of reviews, visits; check inns, which are indirectly acting as a source of marketing for these service providers.

\section{Literature Review}

Solomon and Tuten (2013) stated that both social networks and social communities are the part of marketing zones of social media. The main purpose is to make a strong relationship among the consumers by involving them in conversation, collaboration, and sharing experience with social networking sites members. O'Connor (2011) demonstrated that response of tourism and hospitality in the context to benefit online social network are divided into two aspects: Brand communities made by the person and the person who is engaged to build a relationship with their customers. The target of social networking is considered to be as business-to-consumer or consumer-to-consumer communication. Kwok \& Yu (2013) purposed that under business-to-consumer communication there are various techniques to execute consumer engagement. For example, a different way to deliver messages that would increase the level of likes and comments on Facebook (FB) are uploading pictures or images, writing reviews, sharing information which will pass from many layers which is influencing the person and which will encourage the person to make buying decision via interpersonal influence.

Vollmer \& Precourt (2008) found that social networking sites helped consumers to participate in e-WOM by spreading knowledge about products and services which is based on the personal use of the individual. Chu \& Kim (2011) opined that SNS enables consumers to show their brand preference by liking a brand on Facebook. Due to core features of the internet, it offers interactive and dynamic e-WOM to the consumers, so that they can participate as information seekers, providers, and transmitters. This will entertain, built or develop a social relationship as when it requires the consumer to search social networking sites collect information from friends and relatives regarding the product and make its own purchase decision. Kaplan \& Haenlein (2010) found that the "high level of social presence" as well as self- disclosure in social networking sites for opinion seekers is required which will entertain them to make good judgment. Leenders (2002) explored the social contagion i.e. how people consider the reviews before deciding the purchase decisions. Two processes guide to social contagion: 1- comparison, when people treat others they feel the same as a set of criteria 2-communication when people treat others with whom they are immediately bound as a set of criteria.

Communication involves direct contact between people and their influencers like consumers having a conversation with their relatives on social networking sites about certain kinds of products and services by immediate posting and commenting. Consumers connected with friends and family members suggest their networking circle to follow the specific service providers. Netemeyer, Bearden \& Teel (1989) found that social networking sites provide individual direct and indirect social signals from their squints applicable to the utilization and manipulation of products and services. Talukdar and Dholakia (2004) suggested the utilization (consumption) convergence hypothesis due to globalization there is a likelihood regarding homogeneous utilization behavior certainly, in large connectedness and communication among the people from different parts of the world made feasible by the magnification of information and communication technology. Poon (2008) originates three sets of scales to measure consumers' wish and utilize global brands: conformity to utilization trend, quality perception, and social prestige. Quelch, Holt \& Taylor (2004) found that global brands, utilization activities exhibit on social networking sites by operators around the world are recommended to perform as a distinct case of globally shared utilization symbols among social networks, which allocates the potential usage of the dimensions to measure social networking sites users.

Goldstein and Cialdini (2004) found that conformity addresses change in individual behavior on the behalf of other responses. Amaldoss (2005) defined that Social networking sites play a crucial role in the purchase of explicit products. Aral \& Walker (2012) found that social networking sites are fundamentally changing the direction towards which we communicate, collaborate, consume, and create. It was designed to discover the research on the relationship between social media and business transformation. Bearden \& Netemeyer (1989) defined the expansion of a scale to quantify consumer sensitivity to interpersonal impact is described. Consumer sensitivity to interpersonal impact is hypothesized as a common attribute that alters across individuals and is related to other individual attribute and characteristics.

\section{Research Methodology}

\section{Sampling Design, Sample Size, Sampling Techniques, Sample Locale}

This research has used the primary source to collect the data. To collect the data from the respondents, the study has used a questionnaire as a data collection tool. The non-probability sampling has been used for selecting 
the sample population in this research, in which the study used convenience sampling to tap the target audience. The questionnaire via Google form had been sent to servicemen, businessmen, unemployed \& students. The respondents had been approached by taking the help of friends and relatives so that data can be collected efficiently and accurately. The respondents selected for the process of questionnaire filling belong to the State of Uttar Pradesh and cities such as Mathura, Agra, Firozabad, and Allahabad. The questionnaires had been created via Google form and given to 450 respondents, out of which 332 responses received, leading to a response rate of 73.7\% response rate. On the collected data Exploratory Factor Analysis (EFA) has been used to explore the variable and form the constructs. This is a "dimension reduction" technique that reduced the items into a limited number of factors/constructs.

\section{Population Characteristics}

Out of 332 responses, there are 124 female respondents and 208 male respondents. The Questionnaire was filled by a serviceman, businessman, unemployed \& student, etc. Most of the data is collected from students that were 212 then from serviceman 56 from businessman 41 and unemployed 23. The majority of respondents belong to the age group of 25-35 years followed by 35-45 years whereas very few respondents are above 55 years. 170 respondents have a monthly income between Rs 21000-35000, 87 have a monthly income between Rs 36000- 50000 and the least number of people has income above Rs 50,000.

Table 1. Demographics

\begin{tabular}{llcc}
\hline \multicolumn{2}{c}{ Demographic } & Number & Percentage \\
\hline Gender & Males & 208 & 62.65 \\
Occupation & Females & 124 & 37.35 \\
& Serviceman & 212 & 63.86 \\
& Businessman & 56 & 16.87 \\
Age & unemployed & 23 & 6.93 \\
& Student & 41 & 12.35 \\
& Below 18 years & 20 & 6.02 \\
& $18-25$ & 48 & 14.46 \\
Monthly Income & 25-35 & 125 & 37.65 \\
(INR) & 35-45 & 90 & 27.11 \\
& above 55 years & 8 & 2.41 \\
& Below Rs 20,000 & 45 & 13.55 \\
& Rs 21000-35000 & 170 & 51.20 \\
& Rs 36000-50000 & 87 & 26.20 \\
& Above Rs 50,000 & 30 & 9.04 \\
\hline
\end{tabular}

\section{Data Analysis \& Interpretation}

\section{Scale Reliability Test}

The reliability test examines the relationship of one variable with another variable i.e. inter-consistency of all the variables in the questionnaire. SPSS (Version 20) was used and all the related data was entered into the software. Table 2 Shows the Reliability Statistic for the Datasheet.

Table 2 Reliability Statistics

\begin{tabular}{lll}
\hline Cronbach's Alpha & Cronbach's Alpha Based on Standardized Items & No. of Items \\
\hline 0.754 & 0.794 & 24 \\
\hline
\end{tabular}

\section{Exploratory Factor Analysis}


Exploratory Factor Analysis was applied to explore contributing variable which has a direct and/or indirect impact on restaurant consumption via SNS. Exploratory Factor Analysis is a statistical tool that performs a multivariate analysis and helps a researcher to explore the variable and form the constructs.

\section{KMO and Bartlett's Test of Sphericity}

Sample size adequacy calculated using Kaiser-Meyer-Olkin Measures of sampling adequacy is essential in order to perform Exploratory Factor Analysis. Table 3 highlights that value of the KMO lies in the acceptable range and is acceptable for appropriateness of factor analysis.

Table 3. KMO and Bartlett's Test

\begin{tabular}{lll}
\hline \multicolumn{2}{c}{ Kaiser-Meyer-Olkin Measure of Sampling } & \multicolumn{1}{c}{ Adequacy } \\
\hline $\begin{array}{l}\text { Bartlett's Test of } \\
\text { Sphericity }\end{array}$ & Approx. Chi-Square & $\begin{array}{l}6165.750 \\
903\end{array}$ \\
& Df & 903 \\
& Sig. & .000 \\
\hline
\end{tabular}

\section{Total Variance Explained}

The rule of thumb is to apply the factor analysis when the variables have followed the KMO and Bartlett's test of Sphericity condition. Those factors are extracted having the Eigen Value greater than 1. Table 4 present the details of the extracted factors:

Table 4. Factor Analysis Results

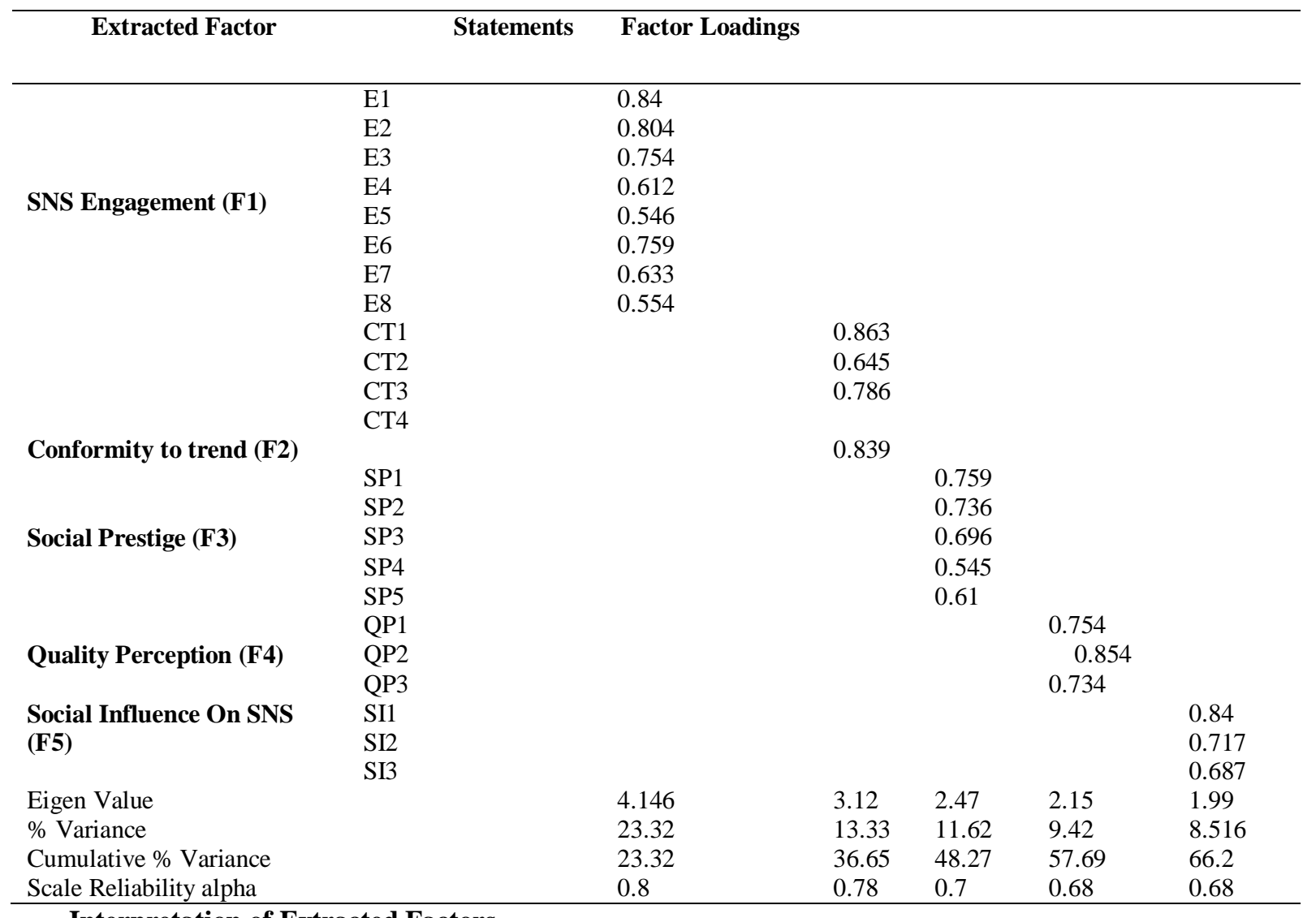

\section{Interpretation of Extracted Factors}

SNS Engagement (F1): It is explained with the help of nine items such as self-efficient to see friends' updates for restaurant-related information on Social Networking Sites (SNS), Exchange views with friends and relatives for restaurant consumption on SNS, Shares thought for restaurant consumption on SNS, Keep in touch with friends on daily basis to share restaurant-related consumption on SNS, effectively connected with friends 
for restaurant consumption on SNS, Consider the opinion with friends which gives positive response about restaurant consumption on SNS, Take suggestion from friends and relatives about restaurant-related consumption on SNS, Friends and relative give their view about restaurant-related consumption from their side and importance of Word Of Mouth (WOM) on the restaurant-related decision via SNS. From extracted can be understood that it talks about the Social Networking Site user to know how it engaged in their daily life. After exploring this factor an idea can be generated that users are keen to exchange their ideas, views, and experience with the help of Social Networking Sites (SNS) Word of Mouth (WOM) somehow plays a crucial role in restaurant related decision.

Conformity to trend (F2): It is explained by four items such as choosing that restaurant which represents global belongingness, selecting that Restaurant which makes comfortable family/friends/relatives, Role of a social group in selecting restaurant, Select restaurant which is famous in SNS After exploring this factor an idea can be generated that SNS participants choose that restaurant which makes them feel comfortable with their family, friends, and relatives also bring them global belongingness, the importance of social group for restaurant consumption on SNS.

Social Prestige (F3): It is explained by five items such as a restaurant which makes a good impact on others, represents my stylish image and makes modification on its lifestyle, focuses on my social status, shows sign. Of honor, after exploring this factor an idea can be generated that SNS participants choose that restaurant which creates a good image on others' minds as well as represents their stylish image and also makes up-gradation or modification on its lifestyle from time to time.

Quality Perception (F4): It is explained by three items such as select that restaurant which provides genuine service, provide extraordinary quality and service is not good but provides a meal at the minimum rate as compared to other restaurants. After exploring this factor an idea can be generated that respondents are very cautious towards the services of the restaurant and they also willing to have some kind of extraordinary quality as well.

Social Influence on SNS (F5): It is explained by three items such as the selection of the restaurant based on positive comment and negative word-of-mouth impact on the market and a new restaurant based on check-in which has been posted by a friend on SNS. After exploring this factor an idea can be generated that Social Networking Site user or SNS user pretty much depends on the friends view or comment on SNS if the positive response comes out from friends or social group about the restaurant than there is a decent chance of selecting that restaurant in nearby future as well as if we talk about Negative WOM about the restaurant than there is a chance that it will decline the market.

\section{Conclusion}

The paper explores the role played by social networking websites affecting the consumer's behavioral attention due to the marketing done by social media websites. Primary data was collected from the respondents which explain that the quality of services plays a major role in maintaining the goodwill of the restaurant. But in any case, the restaurant is not providing genuine kind of services then it will generate negative word of mouth towards the restaurant on the SNS (Social Networking Sites). So for a better image and long-lasting customer relationship, the main focus should be paid on the quality. The restaurant industry should focus on the comfort zone of the customers, any discomfort in ambiance inside or outside can invite the negative WOM. So the restaurant industry must provide a comfort zone to its customers in terms of ambiance, parking space, washrooms, etc. The research found that the restaurant industry should focus on its modification from time to time so that it can create a positive image of the restaurant on Social Networking Sites (SNS). Lastly, the restaurant industry should try to segregate and target the customers based upon their lifestyle taste and preferences, so that they can provide services to customers. This will result in a good image of the restaurant in the eyes of the customer and a happy customer will surely comment positivity about the restaurant on Social Networking Site (SNS).

\section{References}

5. Akehurst, G. (2009). User generated content: The use of blogs for tourism organisations and tourism consumers. Service Business, 3(1), 51-61.

6. Amaldoss, W., \& Jain, S. (2005). Pricing of conspicuous goods: A competitive analysis of social effects. Journal of Marketing Research, 42(1), 30-42. 
7. Aral, S., \& Walker, D. (2012). Identifying influential and susceptible members of social networks. Science, 337(6092), 337-341.

8. Bearden, W.O., Netemeyer, R.G., \& Teel, J.E. (1989). Measurement of consumer susceptibility to interpersonal influence. Journal of Consumer Research, 15(4), 473-481.

9. Bearden, W.O., Netemeyer, R.G., \& Teel, J.E. (1989). Measurement of consumer susceptibility to interpersonal influence. Journal of consumer research, 15(4), 473-481.

10. Chu, S., \& Kim, Y. (2011). Determinants of consumer engagement in electronic word of-mouth (eWOM) in social networking sites. International Journal of Advertising, 30(1), 47-75.

11. Cialdini, R.B., \& Goldstein, N.J. (2004). Social influence: Compliance and conformity. Annual Review of Psychology, 55, 591-621.

12. De Bruyn, A., \& Lilien, G.L. (2008). A multi-stage model of word-of-mouth influence through viral marketing. International journal of research in marketing, 25(3), 151-163.

13. Dellarocas, C. (2003). The digitization of word of mouth: Promise and challenges of online feedback mechanisms. Management science, 49(10), 1407-1424.

14. Dholakia, U.M., \& Talukdar, D. (2004). How social influence affects consumption trends in emerging markets: An empirical investigation of the consumption convergence hypothesis. Psychology \& Marketing, 21(10), 775-797.

15. Harris, L., \& Rae, A. (2009). Social networks: The future of marketing for small business. Journal of Business Strategy, 30(5), 24-31.

16. Hays, S., Page, S., \& Buhalis, D. (2013). Social media as a destination marketing tool: Its use by national tourism organizations. Current Issues in Tourism, 16(3), 211-239.

17. Hermkens, K., Kietzmann, J.H., McCarthy, I.P., \& Silvestre, B.S. (2011). Social media? Get serious! Understanding the functional building blocks of social media. Business horizons, 54(3), 241-251.

18. Holt, D.B., Quelch, J.A., \& Taylor, E.L. (2004). How global brands compete. Harvard business review, 82(9), 68-75.

19. Huang, L. (2012). Social media as a new play in a marketing channel strategy: Evidence from Taiwan travel agencies' blogs. Asia Pacific Journal of Tourism Research, 17(6), 615-634.

20. Hudson, S., \& Hudson, R. (2013). Engaging with consumers using social media: A case study of music festivals. International Journal of Event and Festival Management, 4, 206-223.

21. Kaplan, A.M., \& Haenlein, M. (2010). Users of the world, unite! The challenges and opportunities of social media. Business Horizons, 53(1), 59-68.

22. Kwok, L., \& Yu, B. (2013). Spreading social media messages on Facebook: An analysis of restaurant business-to-consumer communications. Cornell Hospitality Quarterly, 54(1), 84-94.

23. Leenders, R.T.A. (2002). Modeling social influence through network autocorrelation: Constructing the weight matrix. Social Networks, 24(1), 21-47.

24. O’Connor, R.C. (2011). The integrated motivational-volitional model of suicidal behavior.

25. Poon, W.C. (2008). Users' adoption of e-banking services: the Malaysian perspective. Journal of business \& industrial marketing, 23(1), 59-69.

26. Solomon, M.R., \& Tuten, T. (2013). Social Media Marketing: Pearson New International Edition. Pearson Higher Ed.

27. Vollmer, C., \& Precourt, G. (2008). Always on: Advertising, marketing, and media in an era of consumer control. New York, NY: McGraw-Hill. 